
incelenmesi. Aksaray Üniversitesi Sosyal Bilimler Enstitüsü Dergisi, 5(2), 132-147. doi: 10.38122/ased.52.2

Makale Geçmişi / Article History Alindl (Received): 17/07/2021 Kabul edildi (Accepted): 15/12/2021

\title{
Yükseköğretim Ek Ders Ücret Yönetim Süreçleri İçin Geliştirilen Bir Bilişim Sisteminin Kullanılabilirliğinin İncelenmesi
}

\author{
Tark YILMAZ ${ }^{1}$ \\ Selçuk KILIÇ²
}

\begin{abstract}
Öz: Bu çalışmada, yükseköğretim ek ders ücret yönetim süreçlerinde yaşanan sorunların çözümü için geliştirilen bir bilişim sisteminin kullanılabilirliğinin belirlenmesine odaklanılmıştır. Bu amaçla araştırmacılar tarafindan bir bilişim sistemi geliştirilmiştir. Bilişim sistemi uygulamaya konulmadan önce bir öntest yapılarak kullanıcıların ek ders süreçleriyle ilgili karşılaştıkları sorunlar tespit edilmiş ve memnuniyet düzeyleri ölçülmüştür. Sistem devreye alındıktan iki yıl sonra bir sontest uygulanarak mevcut sorunların azalıp azalmadığı belirlenmiş ve bilişim sisteminin kullanılabilirlik düzeyi ölçülmüştür. Elde edilen bulgulardan bilişim sisteminin kullanılabilirlik skorunun kabul edilebilir bir düzeyde olduğu tespit edilmiştir. Sistemin kullanımıyla birlikte sorunların azaldığı ve memnuniyet düzeyinin arttığı görülmüştür. Kullanılabilirlik düzeyi yüksek ürün ve hizmetlerin özellikleri açısından geliştirilen bilişim sistemi değerlendirilmiş ve gelecek araştırmalar için önerilerde bulunulmuştur.
\end{abstract}

Anahtar Kelimeler: Yükseköğretim, Ek Ders Ücret Yönetim Süreci, Bilişim Sistemi, Kullanılabilirlik

\section{Examining the Usability of An Information System Developed for Additional Course Wage Management Processes in Higher Education}

\begin{abstract}
In this study, it is focused on determining the usability of an information system developed for the solution of the problems experienced in higher education additional course wage management processes. For this purpose, an information system was developed by the researchers. Before the information system was put into practice, a pre-test was conducted to identify the problems faced by the users regarding the additional course wage processes, and satisfaction levels were measured. Two years after the system was activated, a posttest was applied to determine whether the existing problems were reduced or not, and the usability of the information system was measured. From the findings, the usability score of the information system was found to be at an acceptable level. With the use of the system, it was observed that the problems decreased and the satisfaction level increased. The information system developed in terms of the features of high availability products and services was evaluated and recommendations were made for future researches.
\end{abstract}

Keywords: Higher Education, Additional Course Wage Management Processes, Information System, Usability

\section{Summary}

Nowadays, the importance of usability concept has increased considerably as technology surrounds our lives with all aspects. The concept of usability was first introduced by Gaines and Shaw (1986) with the idea of ergonomics and physical ease of use. According to the ISO 9241-11: 2018 standard of the International Standards Organization, usability is defined as the effectiveness, efficiency and satisfaction of a system, product or service to be used by certain users in order to achieve the specified goals. In the light of the above definitions, it is thought that in order for an information system to be considered beneficial for human beings, it should save cost and time, be able to fulfill the expected functions, and be reliable and easy to use. Within the scope "of this study, it was aimed to evaluate an information system developed for higher education additional course fee management processes in terms of usability. For this purpose, the following questions were tried to be answered: " 1 . Has the developed information system reduced the general problems

\footnotetext{
${ }^{1}$ Dr. Öğr. Üyesi, Aksaray Üniversitesi, tarikyilmaz@aksaray.edu.tr, ORCID: 0000-0003-1186-8780
}

${ }^{2}$ Dr. Öğr. Üyesi, Aksaray Üniversitesi, selcukkilic@ aksaray.edu.tr, ORCID: 0000-0002-9287-4754 
experienced in additional course management processes?", "2. Has the developed information system reduced the problems experienced in the course load and payroll calculation processes?", "3. Has the developed information system increased the level of satisfaction with the additional course management processes?", "4. How is the usability of the additional course information system?". The information system designed to solve the problems encountered in the additional course management process was developed as web-based and was created by using open-source systems. In this study conducted within the framework of quantitative research paradigm, experimental research design was taken as basis. In order to determine whether the information system developed for the management of additional course processes has reduced the problems faced by the users before, "single group pretest-posttest design", which can be carried out on a single group and is one of the experimental designs, was used. In this study, a pre-test was applied before the additional course information system was put into practice, and a post-test after the application was used successfully for 24 months. The study group of the research consists of 136 instructors who participate in an online questionnaire on a voluntary basis, both in the pre-test and post-test stages, work at a state university and receive additional course wages. In order to obtain quantitative data, two Likert-type scales were developed from the findings obtained in a study previously conducted with qualitative methods by the same researchers. Data were collected from the developed scales both in the pre-test phase and the post-test phase. The first scale, which is called the general problems scale, consists of 11 items related to the problems experienced in the additional course processes. The other scale, called the payroll scale, is a 7-item scale consisting of expressions related to course load calculation and payroll calculation processes. In the posttest stage, System Usability Scale (SUS) consisting of 10 items developed by Brooke (1996) and adapted to Turkish by Çağıltay (2018) was applied to measure how users perceive the usability of the information system. Apart from the scales above, a satisfaction scale ranging from 0-10 points was applied to the participants in the pre-test and post-test stages in order to measure the satisfaction with the execution of the additional course processes. IBM SPSS Statistics v25 and Microsoft Office Excel 2019 programs were used in the analysis of the data. Paired sample t-test was used to determine whether there was a statistically significant difference between the data collected in the pretest and posttest stages. Pearson's correlation analysis was used to determine the relationships between the variables by using the data obtained in the posttest stage. As a result of the t-test conducted in order to see whether the general problems experienced in the additional course management processes, which is the first question of the research, have decreased or not; it was determined that there is a statistically significant difference between the average scores obtained from the pre-test and post-test data. Based on this information, it can be stated that the general problem perceptions of the lecturers regarding the additional course processes have decreased. As a result of the t-test conducted in order to see whether the problems experienced during the course load and payroll calculation process, which is the second question of the research, have decreased; it was seen that there was a statistically significant difference between the average scores obtained from the pre-test and post-test data. Based on this finding, it can be stated that the problem perceptions of the instructors regarding the course load and payroll calculation processes decreased statistically. As a result of the t-test conducted in order to answer the third question of the research (Did the developed information system increase the level of satisfaction with the additional course management processes?); it was determined that there is a statistically significant difference between the average scores obtained from the pre-test and post-test data. Based on this finding, it can be stated that the satisfaction levels of the instructors about the additional course processes have increased statistically. The SUS score was calculated in order to answer the last question of the research and the value obtained (Mean $=67.70, \mathrm{SD}=17.97$ ) is in an acceptable range. In the light of the findings, it was determined that the general problem perceptions of academic staff regarding additional course processes decreased. Similarly, it was found that the problems related to course load and payroll calculation processes decreased with the use of additional course information system. It has been determined that the satisfaction levels of the lecturers with the additional course processes increase with the use of the system. In the light of the findings, it can be evaluated that the additional course information system, which was developed in order to eliminate the problems and dissatisfaction in the additional course processes, in which all transactions are carried out manually and no information system is used, is successful. The limitation of this study is that this system, which is developed with the information systems used in different universities in terms of the management of additional course processes, cannot be compared in terms of usability. It is thought that future studies will make important contributions to the literature by comparing the additional course information systems in different universities in terms of usability with this developed system. 


\section{GIRIŞ}

Günümüzde teknolojinin hayatımızı tüm yönleriyle kuşatması, kullanılabilirlik kavramının önemini oldukça artırmıştır. Kullanılabilirlik kavramı ergonomi ve fiziksel kullanım kolaylığı düşüncesi ile ilk olarak Gaines ve Shaw (1986) tarafindan ortaya çıkarılmıştır. Weinerth, Koenig, Brunner ve Martin (2014) kullanılabilirlik kavramını, belirli bir ortamdaki teknoloji ve kullanıcı arasındaki etkileşimle ilgili bir kavram olarak tanımlamaktadır. İnsan bilgisayar etkileşimi alanının uzmanlarından biri olan Nielson (1993) bundan yaklaşık çeyrek asır önce kullanılabilirlik kavramını, "bir sistemin kullanıcılar tarafından minimum hata oranı ile kullanılabilmesi ve kullanıcılarını memnun edebilmesi için öğrenilebilir ve kolay anımsanabilir, kullanıcı dostu bir arayüze sahip olması" şeklinde tanımlamaktadır.

Literatür incelendiğinde kullanılabilirlik kavramının farklı tanımlar içerdiği görülmektedir. Uluslararası Standartlar Örgütünün ISO 9241-11:2018 standardına göre kullanılabilirlik, "belirli bir kullanım bağlamında belirlenen hedeflere ulaşmak için bir sistemin, ürünün veya hizmetin belirli kullanıcılar tarafindan etkinlik, verimlilik ve memnuniyetle kullanılabilmesi” olarak tanımlanmaktadır. Kullanılabilirlik düzeyi yüksek ürün ve hizmetlerin özellikleri şu şekilde ifade edilmektedir (Çağıltay, 2016; ISO, 2018):

- Verimli, etkili ve memnun edicidir,

- Kolay öğrenilir,

- Farklı yetenek düzeyindeki insanlar tarafindan kullanılabilir,

- Uzun süre kullanımına ara verilse bile, kullanımı kolaylıkla hatırlanır,

- Kullanım hatalarının riskini ve istenmeyen sonuçları azaltır,

- Bakım hizmetlerinin etkin, verimli ve memnuniyetle tamamlanmasını sağlar.

Bir bilişim sisteminin insan için faydalı kabul edilebilmesi için maliyet ve zaman tasarrufu sağlaması, beklenen işlevleri yerine getirebilmesi, güvenilir ve kolay kullanılabilir olması gerektiği düşünülmektedir. Bu çalışma kapsamında yükseköğretim ek ders ücret yönetim süreçleri için geliştirilen bir bilişim sisteminin kullanılabilirlik açısından değerlendirilmesi amaçlanmıştır. Bu amaç doğrultusunda aşağıdaki sorulara yanıt aranmaya çalışılmıştır.

- Geliştirilen bilişim sistemi, ek ders yönetim süreçlerinde yaşanan genel sorunları azaltmış midir?

- Geliştirilen bilişim sistemi, ders yükü ve puantaj hesaplama süreçlerinde yaşanan sorunları azaltmış mıdır? 
- Geliştirilen bilişim sistemi, ek ders yönetim süreçleriyle ilgili memnuniyet düzeyini artırmış midir?

- Ek ders bilişim sisteminin kullanılabilirliği nasıldır?

Ek ders yönetimi sürecinde karşılaşılan problemlerin çözümüne yönelik yapılan bilişim sistemi web tabanlı olarak geliştirilmiş, açık kaynak kodlu sistemlerden yararlanılarak oluşturulmuştur. Sistem tasarımı ve programlama süreçlerinin tamamı araştırmacılar tarafından yürütülmüştür. Her aşamada süreç içinde yer alan bazı öğretim elemanları, bölüm başkanları, okul yöneticileri ve mutemetlerin görüşleri alınarak, beta testleri yapılmıştır. Geliştirilen bilişim sisteminde programlama dili olarak PHP, JavaScript, JQuery ve AJAX yazılım araçları kullanılmıştır. Veri tabanı olarak MySQL veri tabanı kullanılmıştır. Sistemin etkin bir şekilde işleyebilmesi için CentOS 7 işletim sistemi yüklü 8 çekirdekli, 8 GB Ram ve 1 TB depolama alanına sahip bir sunucu kullanılmıştır.

Geliştirilen sistem ana çatı olarak dersi veren öğretim elemanları üzerine kuruludur. Hiyerarşik olarak bölüm başkanlığı daha sonra dekanlık makamları tarafından onaylama süreçlerine sahiptir. Mutemetler sistemde sadece onaylanmış hesaplamaları maliye bakanlığı sistemine girmekle yükümlüdürler. Bunun haricinde başka bir görevleri bulunmamaktadır. Dolayısıyla ek ders ücreti alacak kişi birkaç tuşa basarak hata olup olmadığı, ne kadar ücret alacağını hangi birimlerden ücret alacağını görmekte ve tüm işlemi birkaç dakikada bitirebilmektedir. Böylece bu sistem sayesinde emek ve zaman tasarrufu sağlanmaktadır. Geliştirilen sistem internet üzerinden çevrimiçi çalışan, yetki tanımlarına göre şekillenen bir web otomasyon sistemi olup, her türlü tarayıcıdan ve her türlü cihazdan ulaşılabilir (responsive) durumdadır. Kılıç ve Yılmaz (2021) tarafından yapılan "Yükseköğretim ek ders yönetim süreçlerinde yaşanan problemlerin tespiti ve bir bilişim sistemiyle çözüm önerisi” başlıklı çalışmada önerilen bilişim sisteminin iş akışına uygun olacak şekilde geliştirilen bilişim sistemi, 2016-2017 öğretim yılı bahar yarıyılı başında ek ders süreçlerini yönetmek üzere çalıştırılmaya başlanmıştır. Her eğitim öğretim yılı güz, ara tatil, bahar ve yaz tatili olmak üzere dört farklı dönemden oluşmaktadır. Öğretim elemanları verdikleri dersleri ve ders programlarını otomatik bir şekilde öğrenci otomasyon sisteminden web servisler yardımıyla geliştirilen sisteme yüklerler. Bu durum ek derse esas ödemeyi sağladığı için öğrenci otomasyon sistemindeki olası sorunlarında çözülmesi açısından önemlidir. Ayrıca üniversitede kullanılan bağımsız sistemlerin birbiriyle konuşması açısından da bir örnek teşkil edebilir. Birçok ek ders bilişim sisteminde ders yükü hesaplandıktan ve şablona yerleştirildikten sonra her hafta hesaplama yapılmamakta sadece haftalık şablonun ay içerisindeki haftalara çoğaltılması sonucu puantaj oluşmaktadır. Geliştirilen bilişim sisteminde her ay yapılan puantaj, yasalara ve yönetmeliklere uygun olarak her hafta için ders yükü hesaplanarak oluşturulmaktadır. 
ASED 2021 (Aralık) Cilt:5 Sayl:2

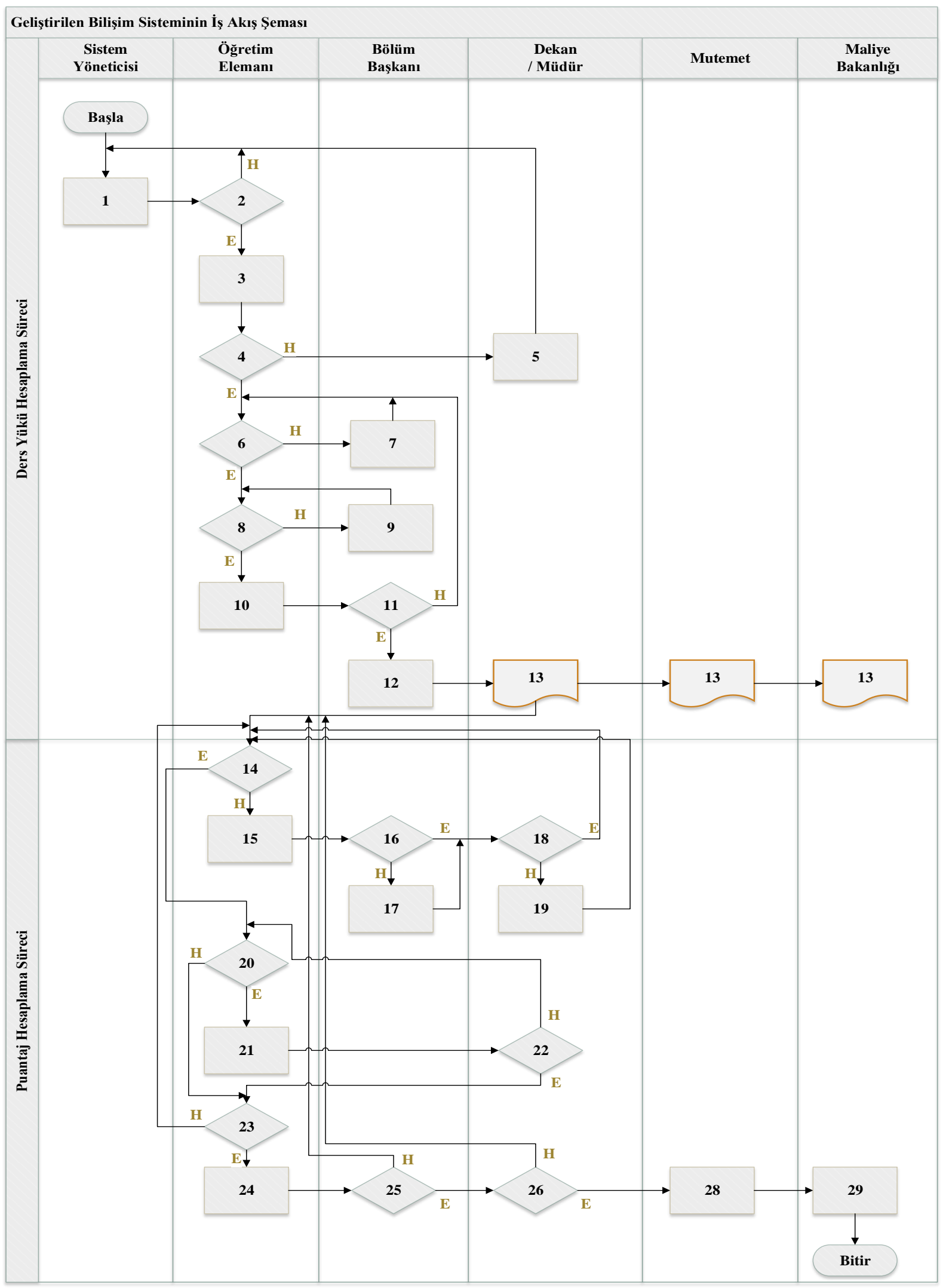

Şekil 1. Geliştirilen bilişim sistemin iş akış şeması 
Tablo 2. Geliştirilen bilişim sistemindeki iş akış adımlarına ilişkin açıklamalar

\section{Adım Numarası ve Açıklaması}

1. Sistem yöneticisi aktif dönemi belirler. Dönem içindeki resmî tatilleri sisteme girer. Öğrenci bilgi sisteminden birimleri, akademisyenleri, dersleri ve ders programlarını web servis üzerinden otomatik olarak çekerek sistemi hazır hale getirir.

2. Öğretim elemanının sisteme kayıtlı olup olmadığının kontrolü yapılır. Öğretim elemanının sisteme kaydı yoksa sistem yöneticisine yönlendirilip kaydının yapılması sağlanır. Varsa, 3. Adıma geçilir.

3. Öğretim elemanı sicil numarası, adı, soyadı, bağlı bulunduğu birim bilgilerini görür. İdari görevi varsa bunu kendisi düzenler, maaş karşılığını ve girmesi gereken ders yükünü sisteme işler.

4. Öğretim elemanı bilgilerinin doğruluğunu kontrol eder. Problem varsa 5. Adıma, yoksa 6. Adıma geçer.

5. Dekan/Müdür bilgileri günceller ve süreç 2. Adıma geri döndürülür.

6. Öğretim elemanı verdiği derslerin kontrolünü yapar. Problem yoksa 8. Adıma, varsa 7. Adıma geçilir.

7. Öğretim elemanının ders verdiği ilgili bölümün başkanı, öğretim elemanının derslerini günceller ve 6. Adıma geri dönülür.

8. Öğretim elemanı ders programını kontrol eder. Problem yoksa 10. Adıma, varsa 9. Adıma geçilir.

9. Öğretim elemanının ders verdiği ilgili bölümün başkanı, öğretim elemanının ders programını günceller ve 8. Adıma dönülür.

10. Öğretim elemanı ders yükü hesaplama butonuna basarak otomatik olarak hesaplanan ders yükü tablosunu kontrol eder ve onaylar.

11. Öğretim elemanının bölüm başkanı, ders yükü tablosunu kontrol eder. Problem yoksa 12. Adıma, varsa 6. Adıma dönülür.

12. Öğretim elemanının bölüm başkanı ders yükü tablosunu onaylar.

13. Dekan/Müdür, mutemet ve Maliye Bakanlığına bağlı olarak çalışan strateji daire başkanlığı ders yükü tablolarının sistemden çıktısını alır. Dekan/Müdür tarafından imzalanan çıktılar strateji daire başkanlığında saklanır.

14. Öğretim elemanı izinli olduğu günleri, saatleri ve telafilerini kontrol eder. İzin ya da telafi yoksa 20. Adıma, varsa 15. Adıma geçilir.

15. Öğretim elemanı izinlerini (idari, rapor, saatlik vb) sisteme işler.

16. Bölüm başkanı öğretim elemanının izinlerini kontrol eder. Problem yoksa 18. Adıma, varsa 17. Adıma geçilir.

17. Öğretim elemanı almış olduğu izinleri girmemişse, bölüm başkanı öğretim elemanının izinlerini sisteme kendisi girer. Süreç 18. Adıma ilerler.

18. Dekan/Müdür öğretim elemanının izinlerini kontrol eder. Problem yoksa 14. Adıma dönülür, varsa 19. Adıma geçilir.

19. Öğretim elemanı almış olduğu izinleri girmemişse, Dekan/Müdür öğretim elemanının izinlerini sisteme kendisi girer. Süreç 14. Adıma döner.

20. Öğretim elemanı telafi kontrolü yapar. Telafi yapılacak ise 21. Adıma, yapılmayacaksa 23. Adıma geçilir.

21. Öğretim elemanı telafi yapacağı dersleri, telafi günlerini ve saatlerini sisteme girer. Sistem tarafından otomatik olarak oluşturulan telafi dilekçesi dekanlığa sunulur ve 22. Adıma geçilir.

22. Dekanlık/Müdürlük öğretim elemanı tarafından sisteme yüklenen telafi programına göre yönetim kurulu tarafından verilen karara göre telafi istediği kabul ya da ret eder. Kabul ederse 23. Adıma, etmezse ret gerekçesiyle beraber 20. Adıma dönülür.

23. Öğretim elemanı aylık puantaj hesaplaması butonuna basmadan önce son olarak izin, telafi kontrolü yapar. Problem yoksa 24. Adıma geçilir, problem varsa 14. Adıma dönülür.

24. Öğretim elemanı puantaj hesaplama butonuna basar. Puantaj hesabının yapıldı̆̆g ilgili ayda hangi birimden ne kadar ücret alacağının bilgisini ekranında görür ve onaylar. 
Tablo 2. Geliştirilen bilişim sistemindeki iş akış adımlarına ilişkin açıklamalar

Adım Numarası ve Açıklaması

25. Bölüm başkanı kendi birimine bağlı öğretim elemanlarının puantaj bilgilerini kontrol eder. Problem varsa ret eder ve süreç 14. Adıma döner. Problem yoksa puantajı onaylar ve 26. Adıma geçilir.

26. Dekan/Müdür kendi biriminde ders veren tüm öğretim elemanlarının puantaj bilgilerini kontrol eder. Problem varsa ret eder ve süreç 14. Adıma döner. Problem yoksa puantajı onaylar ve 27. Adıma geçilir.

27. Mutemet, dekan/müdür tarafından imzalanmak üzere onaylanan puantajların çıktısını alır. Elektronik tablo biçiminde otomatik olarak üretilen dosyayı Maliye Bakanlığının sistemine (KBS) yükler.

28. Maliye Bakanlığı ek ders ödeme işlemleri için gerekli olan diğer süreçleri gerçekleştirir.

Geliştirilen bilişim sisteminin özellikle servis derslerine giren öğretim elemanlarına büyük katkısı bulunmaktadır. Bu dersleri veren öğretim elemanları birçok birimden ders almaktadırlar. Bu durum, çoğu zaman bir gün içerisinde birçok birimde ders almak şeklinde gerçekleşmektedir. Bu tip öğretim elemanlarının izin ve telafi gibi durumları oluştuğunda ek derslerinin hesaplanabilmesi için birim ek ders sorumluları kendi aralarında iletişim kurmak zorunda kalmakta ve çoğu zaman hatalı işlemler gerçekleşebilmektedirler. Geliştirilen sistemde birimler hiyerarşik sistemin kontrol kısmında olduklarından ilgili öğretim elemanının puantaj hesaplamasıyla birlikte tüm birimler diğer birimlerle herhangi bir iletişim kurmadan otomatik bir şekilde durumu kontrol edebilmektedirler. Bu da sistemin diğer birçok sisteme göre daha hızlı ve doğru sonuçlar üretmesini sağlamaktadır.

Geliştirilen sistem öğrenci işleri otomasyonları ile direk bağlantılı olduğundan üniversite içerisinde ders veren öğretim elemanlarının ders verme ile ilgili oluşabilecek tüm senaryolarına göre dinamik matrisler oluşturarak uyum sağlamaktadır. Eğer bir senaryo öğrenci otomasyonunda oluşturulabiliyor ise geliştirilen sistem buna uyum sağlayarak ödemeleri hesaplayabilmektedir. Bu durum öğretim elemanlarına fazla ödeme yapılmasını önlemektedir. Ek ders bilişim sisteminin 2017 Bahar döneminden itibaren 10 dönem boyunca denendiği Aksaray Üniversitesinde Sayıştay tarafından yapılan tüm kontrollerde uygunsuz bir ek ders ödemesine rastlanmadığı Strateji Daire Başkanlığınca teyit edilmiştir.

\section{YÖNTEM}

Nicel araştırma paradigması çerçevesinde yürütülen bu çalışmada, deneysel araştırma deseni esas alınmıştır. Ek ders süreçlerinin yönetimi için geliştirilen bilişim sisteminin, kullanıcıların daha önceden karşılaştıkları problemleri azaltıp azaltmadığını tespit edebilmek için tek grup üzerinde yürütülebilen ve deneysel desenlerden bir olan "tek grup öntest-sontest desen" kullanılmıştır (Büyüköztürk, Akgün, Karadeniz, Demirel ve Kılıç Çakmak, 2012). Bu çalışmada ek ders bilişim sistemi uygulamaya alınmadan önce bir öntest ve uygulamanın başarılı olarak 24 ay kullanılmasından sonra bir sontest uygulanmıştır. Öntest uygulaması 2017 bahar dönemi başında, son test uygulaması ise 2019 bahar dönemi içinde gerçekleştirilmiştir. 


\section{Çalışma Grubu}

Araştırmanın hedeflenen çalışma grubunu Aksaray Üniversitesinde görev yapan ve ek ders ücreti alan 480 öğretim elemanı oluşturmaktadır. Ek ders ücreti alan bütün öğretim elemanlarının katılmasına imkân verilen ve tam sayım hedeflenen yapılandırılmış çevrimiçi bir anket formuna gönüllük esasına göre katılan, hem öntest hem de sontest aşamasında anketi dolduran 136 öğretim elemanı araştırmanın nihai çalışma grubunu oluşturmaktadır. Nihai çalışma grubu, ek ders ücreti alan bütün öğretim elemanlarının yaklaşık \%28'ine tekabül etmektedir. Katılımcıların yaşları 24-73 arasında değişmekte olup, yaş ortalaması 39.43'tür. Yaklaşık \%40’1 kadın ve \%60'ı erkek olan katılımcıların, \%95'i en az doktora derecesine sahip öğretim elemanlarından ve \%5'i öğretim görevlilerinden oluşmaktadır.

\section{Veri Toplama Araçları}

Nicel verilerin elde edilebilmesi için aynı araştırmacılar tarafından daha önce nitel yöntemlerle yapılan bir çalışmada elde edilen bulgulardan Likert tipi iki ölçek geliştirilmiştir. Geliştirilen ölçeklerden hem ön test aşamasında hem de son test aşamasında veri toplanmıştır. Genel sorunlar ölçeği olarak adlandırılan birinci ölçek, ek ders süreçlerinde yaşanan problemlere ilişkin 11 maddeden oluşmaktadır. Puantaj ölçeği olarak adlandırılan diğer ölçek ise ders yükü hesabı ve puantaj hesaplama süreçleri ile ilgili ifadelerden oluşan 7 maddelik bir ölçektir. Ölçeklerin güvenilirliğini test etmek için, Cronbach's Alpha katsayısından yararlanılmıştır. Alpha katsayısının 0.70'in üzerinde olmas1, kabul edilebilir güvenilirlik düzeyini (Nunnally ve Bernstein, 1994), katsayının 0.80'in üzerinde olması ise güvenilirlik düzeyinin yüksek olduğunu göstermektedir (Field, 2005). Ölçeklerin güvenirlik katsayıları 0.80 'in üzerinde olup, Tablo 5 'te verilmektedir.

Sontest aşamasında kullanıcıların bilişim sisteminin kullanılabilirliğini nasıl algıladıklarını ölçmeye yönelik Brooke (1996) tarafından geliştirilen ve Çağıltay (2018) tarafindan Türkçeye uyarlanan 10 maddeden oluşan Sistem Kullanılabilirlik Ölçeği (SKÖ) uygulanmıştır. SKÖ, yazılım ve web tabanlı uygulamalar dahil olmak üzere sistemlerin kullanılabilirliğinin güvenilir şekilde değerlendirilmesini sağlamakta ve algılanan kullanılabilirlik incelemelerinde yaygın olarak kullanılmaktadır (Brooke, 1996; Kadirhan, Gül ve Battal, 2015). Ölçekte bulunan maddelerin beşi olumlu beşi olumsuz ifade içermektedir. SKÖ’nün sonuç puanı 0 ile 100 puan arasında bulunmaktadır (Kuzgun ve Özdinç, 2017).

Yukarıdaki ölçekler dışında ek ders süreçlerinin yürütülmesine ilişkin duyulan memnuniyeti ölçmek amacıyla öntest ve sontest aşamasında katılımcılara 0-10 puan arasında değişen bir memnuniyet ölçeği uygulanmıştır. Memnuniyet ölçeği dışındaki ölçekler, “Kesinlikle Katılmıyorum”, 
"Katılmıyorum", "Ne kat1l1yorum ne kat1lmıyorum", "Kat1l1yorum" ve "Kesinlikle Kat1liyorum" seçeneklerini içeren Likert tipi tutum ölçekleridir.

\section{Verilerin Analizi}

Verilerin analizinde IBM SPSS Statistics v.25 ve Microsoft Office Excel 2019 programları kullanılmıştır. Öntest ve sontest aşamalarında toplanan veriler arasında istatistiki olarak anlamlı fark olup olmadığını tespit edebilmek için bağımlı örneklem t-testinden yararlanılmıştır. Sontest aşamasında elde edilen verilerden yararlanarak genel sorunlar ölçeği, puantaj ölçeği, SKÖ skoru ve memnuniyet düzeyi arasındaki ilişkileri tespit edebilmek için Pearson's korelasyon analizi kullanılmıştır. Analizler öncesinde çalışma grubundan elde edilen verilerin uç değerlere sahip olup olmadığı ve normal dağılım gösterip göstermediği kontrol edilmiştir (Hair, Black, Babin ve Anderson, 2010).

\section{BULGULAR}

Araştırmanın birinci sorusu olan ek ders yönetim süreçlerinde yaşanan genel sorunların azalıp azalmadığını görebilmek amacıyla, hem öntest ve hem de sonteste katılan öğretim elemanlarının genel sorunlara ilişkin verdikleri yanıtların ortalaması yüzdelik oranlara dönüştürülerek Şekil 2'de sunulmaktadır. Şekilden anlaşılacağı üzere, öntest ve sontest aşamasında elde edilen ortalama değerler arasında fark olduğu göze çarpmaktadır. 


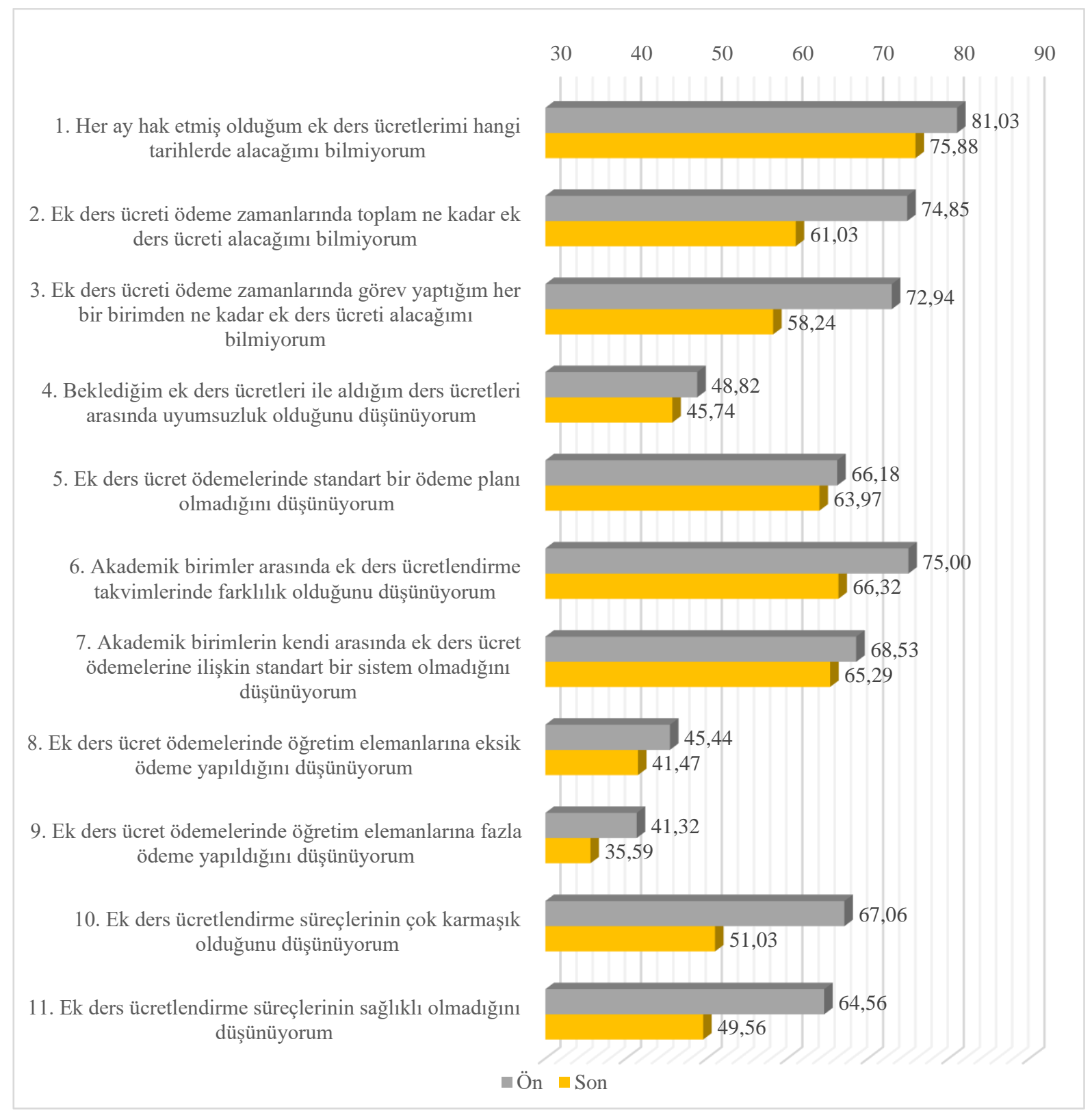

Şekil 2. Öntest ve sontest verilerine göre genel sorunlar algısındaki değişim

Ek ders süreçlerine yönelik genel sorun algısında görülen olumlu farkın istatistiki olarak anlamlı olup olmadığını test etmek amacıyla yapılan bağımlı örneklem t-testi sonuçları Tablo 1'de sunulmaktadır.

Tablo 1. Genel sorun algısı bağımlı örneklem t-testi sonuçları (öntest-sontest)

\begin{tabular}{lccccc}
\hline Değişkenler & Ortalama fark & Standart sapma & t & sd & p \\
\hline Ön Genel Sorun - Son Genel Sorun & 4.581 & 11.846 & 4.510 & 135 & 0.000 \\
\hline
\end{tabular}

Tablodan anlaşılacağı üzere, öntest ve sontest verilerinden elde edilen ortalama puanlar arasında istatistiki olarak anlamlı bir fark bulunmaktadır $\left(\mathrm{t}_{(135)}=4.510 ; \mathrm{p}<0.05\right)$. Etki büyüklüğü Cohen's d istatistiği kullanılarak hesaplanmış ve değeri 0.39 olarak bulunmuştur. Bu değerin orta düzeyde bir etki büyüklügüne sahip olduğu ifade edilebilir (Cohen, 1988). Ortalama farkın pozitif değer alması 
(Ort. Fark=4.581), sontestten elde edilen ortalama puanların öntestten elde edilen ortalama puanlardan daha düşük olduğunu göstermedir. Bu bulgudan hareketle öğretim elemanlarının ek ders süreçlerine yönelik genel sorun algılarının istatistiki olarak azaldığg ifade edilebilir.

Araştırmanın ikinci sorusu olan ders yükü ve puantaj hesaplama sürecinde yaşanan problemlerin azalıp azalmadığını görebilmek amacıyla, hem öntest ve hem de sonteste katılan öğretim elemanlarının verdikleri yanıtların ortalaması yüzdelik oranlara dönüştürülerek Şekil 3'te sunulmaktadır. Şekilden anlaşılacağı üzere, öntest ve sontest aşamasında elde edilen ortalama değerler arasında fark olduğu görülmektedir.

1. Ek Ders Sisteminde aylık ek ders puantaj tablosunu hazırlamak benim için zordur.

2. Ek Ders Sisteminde aylik ek ders puantaj tablosunu hazırlama konusunda yeterli bilgiye sahip değilim.

3. Ek Ders Sisteminde aylik ek ders puantaj tablosunu hazırlamak için yardım alırım.

4. Ek Ders Sisteminde aylık ek ders puantaj tablosunu hazırlamak benim için zaman kaybına neden olur.

5. Ek Ders Sisteminde aylık ek ders puantaj tablosunu hazırlama süreci çok karmaşıktır.

6. Ek Ders Sisteminde aylık ek ders puantaj tablosunu hazırlanırken çok fazla bürokratik adım gerekmektedir.

7. Ek Ders Sisteminde aylık ek ders puantaj tablosunu hatasız bir șekilde hazırlayabilen sayısı çok azdır.

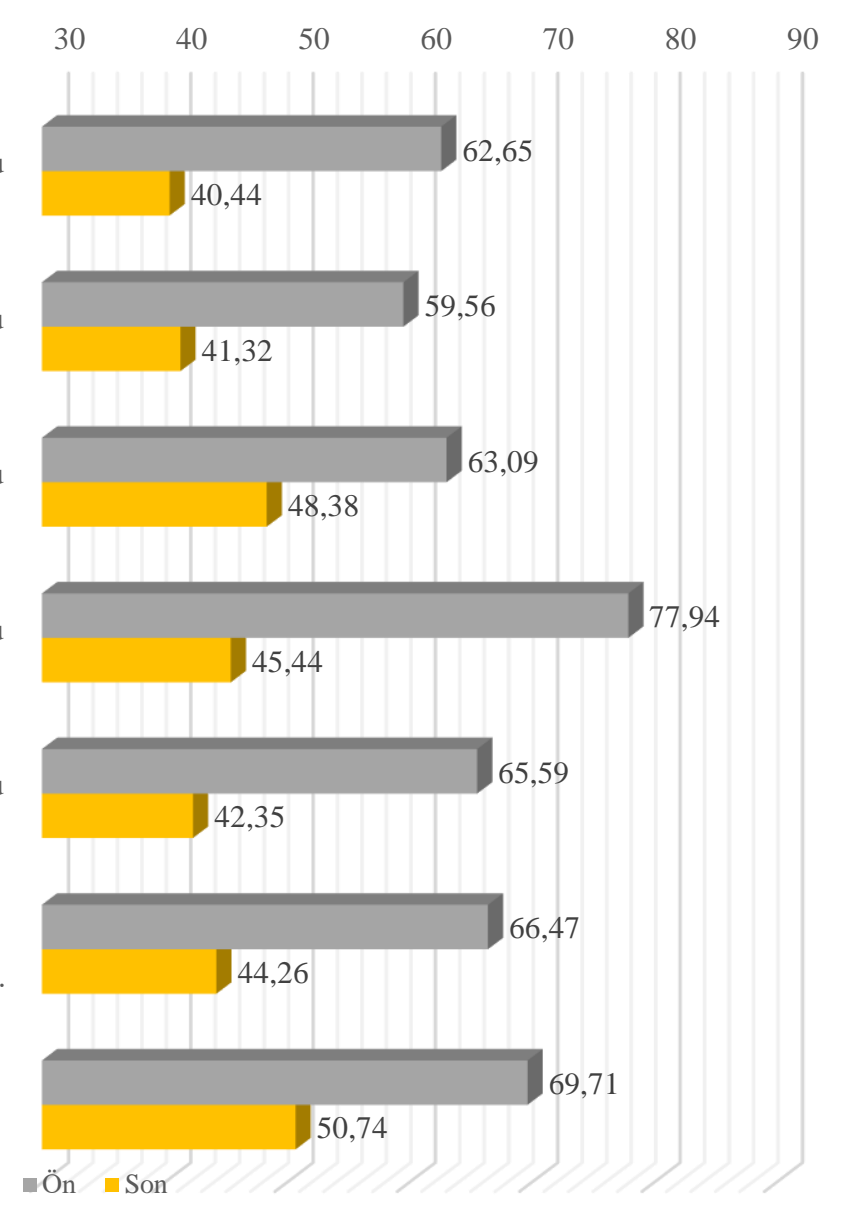

Şekil 3. Öntest ve sontest verilerine göre ders yükü ve puantaj hesaplama ile ilgili sorun algısındaki değişim

Ders yükü ve puantaj hesaplama ile ilgili sorun algısında görülen olumlu farkın istatistiki olarak anlamlı olup olmadığını test etmek amacıyla yapılan bağımlı örneklem t-testi sonuçları Tablo 2'de sunulmaktadır.

Tablo 2. Ders yükü ve puantaj hesaplama ile ilgili sorun algısı bağımlı örneklem t-testi sonuçları (öntest-sontest)

\begin{tabular}{lccccc}
\hline Değişkenler & Ortalama fark & Standart sapma & t & sd & p \\
\hline Ön Puantaj - Son Puantaj & 7.596 & 8.362 & 10.594 & 135 & 0.000 \\
\hline
\end{tabular}


Tablodan anlaşılacağı üzere, öntest ve sontest verilerinden elde edilen ortalama puanlar arasında istatistiki olarak anlamlı bir fark bulunmaktadır $\left(\mathrm{t}_{(135)}=10.594 ; \mathrm{p}<0.05\right)$. Etki büyüklüğü Cohen's d istatistiği kullanılarak hesaplanmış ve değeri 0.91 olarak bulunmuştur. Bu değer, geniş bir etki büyüklüğüne sahip olduğu yönünde yorumlanmaktadır (Cohen, 1988). Ortalama farkın pozitif değer alması (Ort. Fark=7.596), sontestten elde edilen ortalama puanların öntestten elde edilen ortalama puanlardan daha düşük olduğunu göstermedir. Bu bulgudan hareketle öğretim elemanlarının ders yükü ve puantaj hesaplama süreçlerine yönelik sorun algılarının istatistiki olarak azaldığı ifade edilebilir.

Araştırmanın üçüncü sorusuna (geliştirilen bilişim sistemi, ek ders yönetim süreçleriyle ilgili memnuniyet düzeyini artırmış mıdır?) yanıt verebilmek amacıyla hem öntest ve hem de sonteste katılan öğretim elemanlarının SKÖ ölçeği dışındaki tüm ölçeklere verdikleri yanıtların ortalaması yüzdelik oranlara dönüştürülerek Şekil 4'te sunulmaktadır. Şekilden anlaşılacağı üzere, ek ders süreçleriyle ilgili memnuniyet düzeyi öntest ve sontest aşamasında elde edilen ortalama değerler arasında fark olduğu görülmektedir.

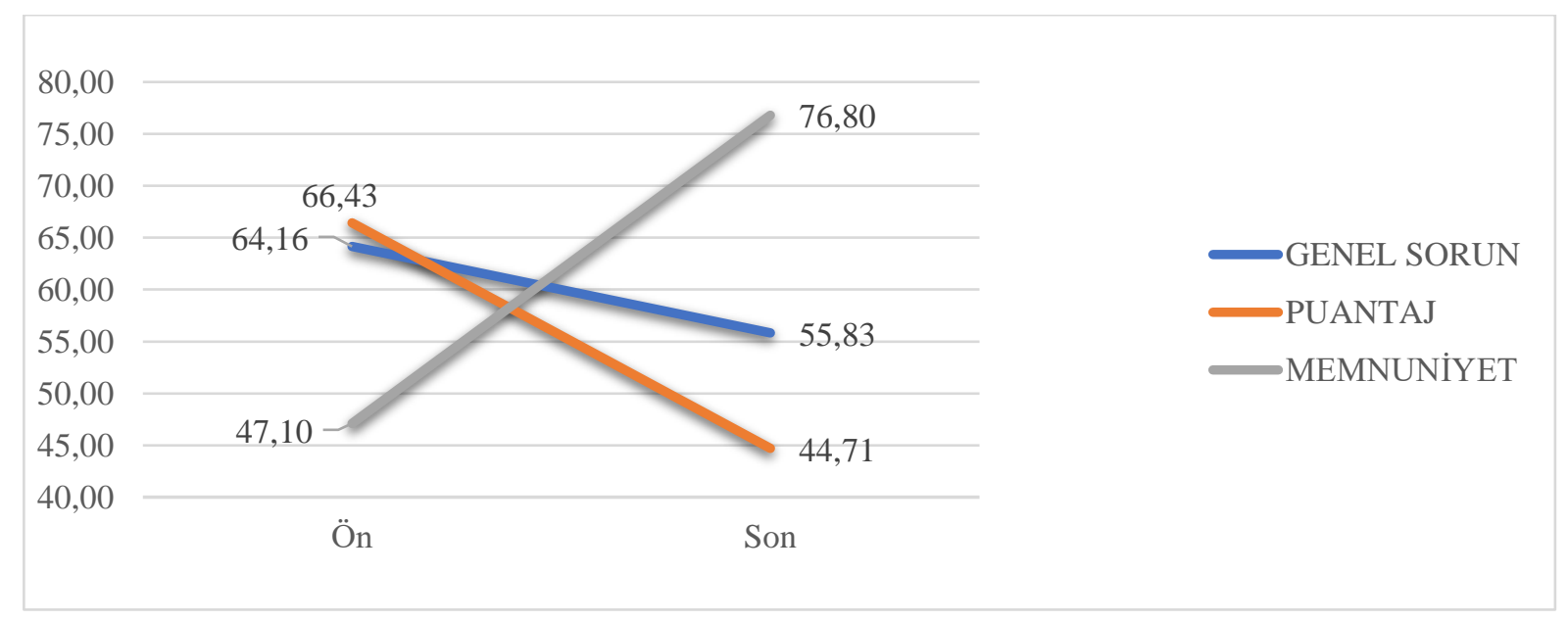

Şekil 4. Genel sorunlar, ders yükü-puantaj hesaplama sorunları ve memnuniyet düzeyindeki değişim

Ek ders süreçlerine yönelik memnuniyet düzeyinde görülen olumlu farkın istatistiki olarak anlamlı olup olmadığını test etmek amacıyla yapılan bağımlı örneklem t-testi sonuçları Tablo 3'te sunulmaktadir.

Tablo 3. Memnuniyet düzeyindeki değişimi belirlemeye yönelik yapılan bağımlı örneklem t-testi sonuçları (öntest-sontest)

\begin{tabular}{lccccc}
\hline Değişkenler & Ortalama fark & Standart sapma & $\mathbf{t}$ & sd & p \\
\hline Ön Memnuniyet - Son Memnuniyet & -2.971 & 2.686 & -12.898 & 135 & 0,000 \\
\hline
\end{tabular}

Tablodan anlaşılacağı üzere, öntest ve sontest verilerinden elde edilen ortalama puanlar arasında istatistiki olarak anlamlı bir fark bulunmaktadır $\left(\mathrm{t}_{(135)}=-12.898 ; \mathrm{p}<0.05\right)$. Etki büyüklüğü Cohen's d istatistiği kullanılarak hesaplanmış ve değeri 1.11 olarak bulunmuştur. Bu değer, çok geniş bir etki 
büyüklüğüne sahip olduğu yönünde yorumlanmaktadır (Cohen, 1988). Ortalama farkın ve t değerinin negatif değer alması (Ort. Fark=-2.971), sontestten elde edilen ortalama puanların öntestten elde edilen ortalama puanlardan daha yüksek olduğunu göstermedir. $\mathrm{Bu}$ bulgudan hareketle öğretim elemanlarının ek ders süreçlerine yönelik memnuniyet düzeylerinin istatistiki olarak arttığı ifade edilebilir.

Araştırmanın son sorusuna (ek ders bilişim sisteminin kullanılabilirliği nasıldır?) yanıt verebilmek için SKÖ skoru hesaplanarak Tablo 4’te sunulmuştur.

Tablo 4. SKÖ skoruna ilişkin istatistikler

\begin{tabular}{lccc}
\hline Ölçek & N & Ortalama & Standart Sapma \\
\hline SKÖ Skoru & 136 & 67.70 & 17.97 \\
\hline
\end{tabular}

Bangor, Kortum ve Miller (2008)'e göre elde edilen değer (Ort.=67.70, SS=17.97), ikinci çeyrek içerisinde ve yüksek marjinal kabul edilebilir aralıkta bulunmaktadır. Diğer bir ifadeyle elde edilen skor, Şekil 5'teki (GOOD) noktasının çok yakınında yer almaktadır. Sonuç olarak mantıklı bir çıkarımla elde edilen skorun ortalama düzeyde kabul bölgesinde yer aldığı söylenebilecektir.

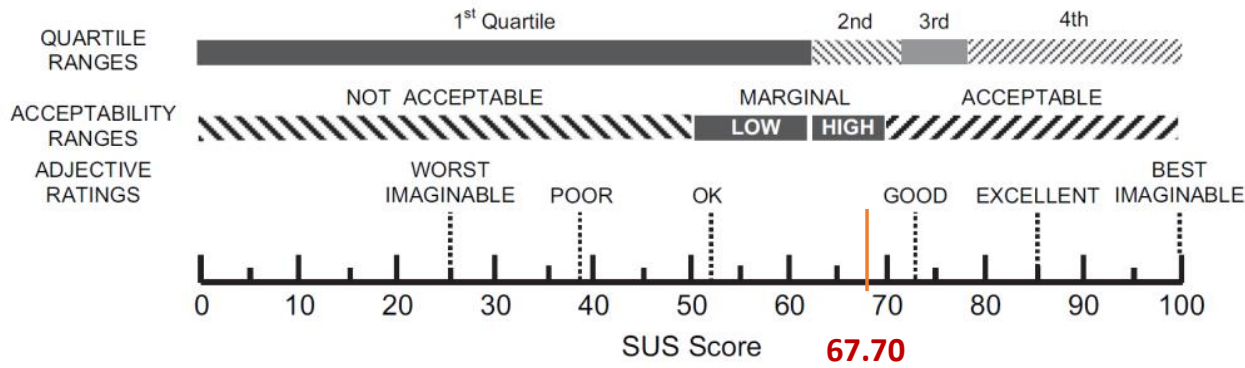

Şekil 5. SKÖ skorunun değerlendirilmesi

Sistem uygunluk skoru ile diğer değişkenler arasındaki ilişkileri tespit edebilmek amacıyla yapılan korelasyon analizinin sonuçları Tablo 5'te sunulmaktadır. Değişkenlerin kesişim noktalarında Cronbach's Alpha güvenirlik katsayıları verilmiştir.

\begin{tabular}{lc|c|c|c|c|c|c}
\hline Değişkenler & $\mathbf{1}$ & $\mathbf{2}$ & $\mathbf{3}$ & $\mathbf{4}$ & $\mathbf{5}$ & $\mathbf{6}$ & $\mathbf{7}$ \\
\hline 1. Ön Genel Sorun & .849 & & & & & & \\
\hline 2. Son Genel Sorun & .158 & .870 & & & & & \\
\hline 3. Ön Puantaj & $.335^{* *}$ & .000 & .853 & & & & \\
\hline 4. Son Puantaj & .036 & $.339^{* *}$ & .116 & .922 & & & \\
\hline 5. Ön Memnuniyet & $-.288^{* *}$ & -.045 & -.164 & $.178^{*}$ & 1 & & \\
\hline 6. Son Memnuniyet & $-.175^{*}$ & $-.300^{* *}$ & -.052 & $-.439^{* *}$ & -.022 & 1 & \\
\hline 7. SKÖ & -.116 & $-.367^{* *}$ & -.080 & $-.669^{* *}$ & -.126 & $.649^{* *}$ & .861 \\
\hline
\end{tabular}

**Korelasyon 0.01 düzeyinde anlamlıdır. * Korelasyon 0.05 düzeyinde anlamlıdır.

Tablodan anlaşılacağı üzere sistem kullanılabilirlik düzeyi ile ek ders süreçlerinde yaşanan genel sorunlar arasında $(\mathrm{r}=-.367, \mathrm{p}<.01)$ istatistiki olarak anlamlı ve negatif bir ilişki bulunmaktadır. Benzer şekilde kullanılabilirlik düzeyi ile ders yükü ve puantaj hesaplama süreçleri ile ilgili sorunlar algısı 
arasında istatistiki olarak anlamlı ve negatif bir ilişki bulunmaktadır $(\mathrm{r}=-.669, \mathrm{p}<.01)$. Ayrıca, kullanılabilirlik düzeyi ile öğretim elemanlarının ek ders süreçleri ile ilgili memnuniyet düzeyleri arasında istatistiki olarak anlamlı ve pozitif bir ilişkinin varlı̆̆ tespit edilmiştir $(\mathrm{r}=.649, \mathrm{p}<.01)$. Öntest ve sontest aşamasında elde edilen verilerden ulaşılan bulgulardan, her bir değişkenin öntest ve sontest puanları arasında istatistiki olarak anlamlı bir ilişki tespit edilememiştir. Yapılan bağımlı örneklem t-testi sonuçlarıyla uyumlu bir bulguya ulaşılmıştır.

\section{SONUÇ VE TARTIŞMA}

Elde edilen bulgular 1şı̆̆ında, 2017 bahar dönemi başında öğretim elemanlarının ek ders süreçlerine yönelik genel sorun algılarının 2019 bahar dönemi içinde azaldığı tespit edilmiştir. Benzer şekilde ders yükü ve puantaj hesaplama süreçleriyle ilgili sorunların ek ders bilişim sisteminin kullanımıyla birlikte azaldığı saptanmıştır. Öğretim elemanlarının ek ders süreçlerine yönelik memnuniyet düzeylerinin sistemin kullanımıyla birlikte arttığı tespit edilmiştir. Elde edilen bulgulara göre sistem kullanılabilirlik düzeyi arttıkça, ek ders süreçlerinde yaşanan genel sorunlar, ders yükü ve puantaj hesaplama süreçleri ile ilgili sorunların azaldığı tespit edilmiştir. Kullanılabilirlik düzeyi arttıkça, öğretim elemanlarının ek ders süreçleri ile ilgili memnuniyet düzeylerinin de arttı̆̆ı görülmüştür. Elde edilen bulgular ve gözlemler ışığında; geliştirilen bilişim sisteminin, kullanılabilirlik düzeyi yüksek ürün ve hizmetlerin özellikleri açısından Tablo 6'da değerlendirilmektedir.

Tablo 6. Geliştirilen sistemin kullanılabilirlik düzeyi yüksek ürün ve hizmetlerin özellikleri açısından değerlendirilmesi

Özellikler Kullanılabilirlik Düzeyinin Değerlendirilmesi

Verimli, etkili ve memnun Bilişim sisteminde tutulan kayıtlardan; bir öğretim elemanının ders yükü tablosu hazırlama edicidir süresi kontroller dahil olmak üzere ortalama 45 saniyede, puantaj hesaplama süresi ise 3 saniyede gerçekleştirilebilmektedir. Bütün öğretim elemanları aynı anda işlem yapsa bile sürenin değişmediği görülmektedir. Bunun nedeni de tarayıcı üzerinden önbellekleme aracılığıyla işlemlerin yapılması ve sunucu üzerine fazla yük bindirmemesinden kaynaklanmaktadır. Sonuç olarak yaklaşık 60 saniye içerisinde tüm üniversitenin ek ders hesaplama süreci teorik olarak gerçekleştirilebilmektedir. Buradan hareketle geliştirilen sistemin etkililik ve verimlilik açısından uygun olabileceği düşünülebilir. Elde edilen bulgulardan memnuniyet düzeyinde artışın yaklaşık \%63 arttığı görülmüştür.

Kolay öğrenilir

Kullanıcılar için dişarıdan veri girişleri web servisler aracılığıyla öğrenci bilgi sisteminden otomatik olarak çekildiğinden, bilişim sistemi hesaplamalarını kontrol et ve onayla şeklinde yapmaktadır. Çok özel sorunlar oluşmaması durumunda hiç bilgisi olmayan bir kullanıcının bile sistemi rahatlıkla kullanabildiği gözlemlenmiştir. Sistemde bulunan yardım sayfalarına kullanıcıların yalnızca \%8'lik bir kısmının bakması sistemin kolay bir şekilde öğrenilebildiğini göstermektedir. Elde edilen bulgulardan sistem kullanılabilirlik düzeyinin kabul edilebilir düzeyde çıkması bu durumu teyit etmektedir.

Farklı yetenek düzeyindeki Geliştirilen sistemi, üniversitede her biri farklı yetenek düzeyinde, farklı disiplinlerde ve insanlar tarafindan kullanılabilir farklı yaşlarda bulunan profesör, doçent, doktor öğretim üyesi ve öğretim görevlisi kadrosunda bulunan öğretim elemanları ile memur kadrosunda bulunan mutemetler rahatlıkla kullanabilmektedir. Sistem üzerinde bulunan sorun bildir kısmını yaklaşık 24 ay 
Tablo 6. Geliştirilen sistemin kullanılabilirlik düzeyi yüksek ürün ve hizmetlerin özellikleri açısından değerlendirilmesi

\begin{tabular}{ll}
\hline Özellikler & Kullanılabilirlik Düzeyinin Değerlendirilmesi \\
\hline & $\begin{array}{l}\text { boyunca kullanan tekil kişi sayısı bölüm başkanları ve mutemetler dahil edildiğinde sistemin } \\
\text { kullanılmaya başlandığı ilk dönemde } 64 \text { olarak tespit edilmiştir. }\end{array}$ \\
\hline $\begin{array}{l}\text { Uzun süre kullanımına ara } \\
\text { verilse bile, kullanımı } \\
\text { kolaylıkla hatırlanır }\end{array}$ & $\begin{array}{l}\text { Geliştirilen sistem } 24 \text { ay boyunca kullanılmıştır bu süre içerisinde güz, bahar, ara tatil ve } \\
\text { yaz dönemi olmak üzere } 8 \text { adet dönem bulunmaktadır. Sistem kullanıcıları, uzmanlık alan } \\
\text { dersi alan öğretim elemanlarının sistemi } 8 \text { defa ders yükü hesabı ve 24 defa puantaj için } \\
\text { kullanmıştır. Uzmanlık alan dersi olmayan diğer öğretim elemanlarının } 4 \text { kez ders yükü } \\
\text { hesabı ve 20 kez puantaj için kullanmıştır. Ayda bir kez kullanılmasına rağmen, sistem } \\
\text { üzerinde bulunan sorun bildir kısmını son 12 ayda yalnızca 10 tekil kişi kullanmıştır. Bu } \\
\text { durum sistemin uzun süre ara verilse bile rahatlıkla hatırlandığgnı göstermektedir. }\end{array}$ \\
\hline
\end{tabular}

Kullanım hatalarının riskini Sistem devreye alındıktan sonra daha önce manuel olarak yürütülen ders yükü ve puantaj ve istenmeyen sonuçları hesaplama süreçlerinde yaşanan hatalar ve istenmeyen durumlar tamamen ortadan azaltır kaldırılmıştır. Geliştirilen sistem, otonom olarak çalışmakta ve yalnızca kontrol et - onayla işlemleriyle sürecin yönetilmesini sağlamaktadır. Bu durum kullanıcıların hata yapmasına olanak vermemektedir. Son iki yıl içerisinde Strateji Daire Başkanlığından alınan geri bildirimlerden üniversitede ek ders ücreti ödemeleriyle ilgili herhangi bir olumsuz durum ile karşılaşılmamıştır.

Bakım hizmetlerinin etkin, Üniversitenin kendi sunucu altyapısı içerisinde çalışan bu sistem için herhangi bir bakım verimli ve memnuniyetle tamamlanmasını sağlar

hizmeti gerekmemektedir. Geliştirilen yazılımlar aracılığıyla her dönem başında veri tabanı bakımları otomatik olarak yapılmakta ve yedekleme sunucusuna otomatik olarak yüklenmektedir. Bu işlemler için herhangi bir bireye ihtiyaç duymaksızın sistem otonom olarak işlemektedir. Sistemin çalışabilmesi için ihtiyaç duyulan diğer altyapı hizmetleri üniversitenin bilgi işlem daire başkanlığınca yürütülmektedir. Herhangi bir kişiye ya da kuruma bu işlemler için farklı bir lisans ücreti ya da aidat ödenmemektedir.

Özetle; geliştirilen sistemin yardım menüsü okunmadan kolaylıkla öğrenilebildiği, farklı yetenek düzeyindeki bireylerin tarafından rahatlıkla kullanılabildiği anlaşılmaktadır. Sistemin kullanılabilirlik açısından en önemli özelliğinin öğretim elemanı düzeyindeki kullanıcıların hata yapmasına olanak vermemesidir. ISO 9241-11:2018 standartlarına göre geliştirilen bilişim sisteminin kullanılabilirlik açısından yeterli olduğu söylenebilir (ISO, 2018).

2017 bahar dönemi öncesinde herhangi bir bilişim sisteminin kullanılmadığı, bütün işlemlerin manuel olarak yürütüldüğü ek ders süreçlerinde yaşanan sorunların ve memnuniyetsizliklerin giderilmesi amacıyla geliştirilen ek ders bilişim sisteminin ulaşılan bulgular 1şı̆̆ında başarılı olduğu değerlendirilebilir. Ek ders süreçlerinin yönetimi konusunda farklı üniversitelerde kullanılan bilişim sistemleri ile geliştirilen bu sistemin kullanılabilirlik açısından karşılaştırılmaması bu çalışmanın sınırlılığını oluşturmaktadır. Gelecek araştırmalarda geliştirilen bu sistem ile farklı üniversitelerdeki ek ders bilişim sistemlerinin kullanılabilirlik açısından karşılaştırıldığı çalışmalar yapılabilir. 


\section{KAYNAKLAR}

Bangor, A., Kortum, P. T. ve Miller, J. T. (2008). An empirical evaluation of the system usability scale. International Journal of Human-Computer Interaction, 24(6), 574-594. doi: $10.1080 / 10447310802205776$

Brooke, J. (1996). SUS: A "quick and dirty" usability scale. İçinde P. W. Jordan, B. Thomas, B. A. Weerdmeester ve A. L. McClelland (Ed.), Usability Evaluation in Industry. London: Taylor and Francis.

Büyüköztürk, Ş., Akgün, Ö. E., Karadeniz, Ş., Demirel, F. ve Kılıç Çakmak, E. (2012). Bilimsel Araştırma Yöntemleri (13. Baskı). Ankara: Pegem Akademi.

Cohen, J. (1988). Statistical power analysis for the behavioral sciences (2. Bask1). Hillsdale, NJ: Lawrence Earlbaum Associates.

Çağıltay, K. (2016). İnsan bilgisayar etkileşimi ve eğitim teknolojileri. İçinde K. Çağıltay ve Y. Göktaş (Ed.), Öğretim Teknolojilerinin Temelleri: Teoriler Araştırmalar Eğilimler (2 Baskı., ss. 297-314). Ankara: Pegem Akademi.

Çağıltay, K. (2018). Inssan bilgisayar etkileşimi ve kullanılabilirlik mühendisliği: Araştırma örnekleri - Veri toplama araçları - ISO 9241 standartları çerçevesi (2. Baskı). Ankara: Seçkin Yayıncılık.

Field, A. (2005). Discovering statistics using SPSS (2. Bask1). London: Sage.

Gaines, B. R. ve Shaw, M. L. G. (1986). From timesharing to the sixth generation: the development of human-computer interaction. Part I. International Journal of Man-Machine Studies, 24(1), 1-27. doi: https://doi.org/10.1016/S0020-7373(86)80037-2

Hair, J., Black, W. C., Babin, B. J. ve Anderson, R. E. (2010). Multivariate data analysis (7. Bask1). Upper Saddle River, New Jersey: Pearson Education International.

ISO. (2018). Ergonomics of human-system interaction Part 11: Usability: Definitions and concepts (Vol. ISO 9241-11:2018). the International Organization for Standardization: https://www.iso.org/obp/ui/\#iso:std:iso:9241:-11:ed-2:v1:en.

Kadirhan, Z., Gül, A. ve Battal, A. (2015). Sistem kullanılabilirlik ölçeği: Geçerlik ve güvenirlik çalışması. Eğitim Bilimleri ve Uygulama, 14(28), 149-167.

Kılıç, S. ve Yılmaz, T. (2021). Yükseköğretim ek ders yönetim süreçlerinde yaşanan problemlerin tespiti ve bir bilişim sistemiyle çözüm önerisi. Aksaray Üniversitesi Sosyal Bilimler Enstitüsü Dergisi, 4(1).

Kuzgun, H. ve Özdinç, F. (2017). Eğitsel sosyal ağ ortamı Edmodo'nun kullanılabilirliğinin incelenmesi. Kuramsal Eğitimbilim Dergisi, 10(2), 274-297.

Nielson, J. (1993). Usability engineering. London: Academic Press Limited.

Nunnally, J. C. ve Bernstein, I. H. (1994). Psychometric Theory (3. Bask1). New York: McGraw-Hill.

Weinerth, K., Koenig, V., Brunner, M. ve Martin, R. (2014). Concept maps: A useful and usable tool for computer-based knowledge assessment? A literature review with a focus on usability. Computers \& Education, 78, 201-209. doi: https://doi.org/10.1016/j.compedu.2014.06.002 